Т. М. Муратова, О. М. Лебідь, Д. М. Храмцов, С. М. Олійник, Ю. М. Ворохта, I. Г. Чемересюк, О. І. Варбанець Одеський національний медичний університет, м. Одеса

\title{
НАВЧАННЯ В ІНТЕРНАТУРІ ЗА ФАХОМ “НЕВРОЛОГІЯ": СУЧАСНІ ТЕХНОЛОГІЇ ТА ПЕРСПЕКТИВИ ЇХ ЗАСТОСУВАННЯ
}

\author{
T. M. Muratova, O. M. Lebid, D. M. Khramtsov, S. M. Oliinyk, Yu. M. Vorokhta, \\ I. G. Chemeresyuk, O. I. Varbanets \\ Odesa National Medical University

\section{EDUCATION IN INTERNSHIP ON NEUROLOGY: MODERN} \\ TECHNOLOGIES AND PROSPECTS FOR THEIR APPLICATION
}

\begin{abstract}
Мета роботи - оцінка перспектив застосування сучасних інформаційних технологій при навчанні в інтернатурі за фахом “Неврологія".

Основна частина. Проведений аналіз застосування інформаційних технологій у викладанні фахових дисциплін лікарямінтернам, що займаються за спеціальністю “Неврологія”. Основними формами є засоби програмованого контролю, електронні підручники, телеконференції, застосування мультимедійних симуляційних технологій, розсилки навчальних матеріалів в електронному вигляді, електронні шаблони медичної документації для курації пацієнтів та використання електронних репозиторіїв. Технологія BODY INTERACT TM надає можливість інтеграції у процес вивчення новітніх досягнень медицини та інформаційних технологій, розробки навчальних концепцій та обміну досвідом через реальні клінічні ситуації, створюючу основу для культури відкритих комунікацій і співробітництва. Академічна успішність інтернів упродовж періоду спостереження на проміжних контролях відповідала медіані 4 (3;4), на кінцевих - 4 (3;5). Результати опитування показали зростання зацікавленості інтернів у застосуванні інформаційних технологій при викладанні фахових дисциплін. На кафедрі неврології Одеського національного медичного університету на всіх етапах підготовки інтернів активно застосовуються засоби програмованого контролю. Показана доцільність регулярного перегляду навчальних програм для навчання лікарів-інтернів з фаху “Неврологія” з урахуванням можливостей сучасних інформаційних технологій

Висновок. Врахування пріоритетів підготовки лікарів-інтернів за фахом “Неврологія” із широким впровадженням сучасних інформаційних технологій дозволяє вдосконалити теоретичні знання та практичні навички, оптимізувати взаємодію у форматі мультидисциплінарної команди з фахівцями інших спеціальностей.
\end{abstract}

Ключові слова: післядипломна освіта; інформаційні технології; неврологія.

The aim of the work - to assess the prospects for the use of modern information technologies in internship in the field of Neurology. The main body. An analysis of the application of information technologies in the teaching of professional disciplines to interns, specializing in Neurology is conducted. The main forms are programmed control tools, electronic textbooks, teleconferencing, multimedia simulation technologies, electronic educational materials distribution, electronic medical records templates for patients' management and the use of electronic repositories. BODY INTERACT TM technology provides the opportunity to integrate into the process of learning the latest advances in medicine and information technology, developing learning concepts and sharing experiences through real clinical situations, creating a foundation for the culture of open communication and collaboration. Academic success of interns during the monitoring period on interim controls corresponded to the median $4(3 ; 4)$, in the final $-4(3 ; 5)$. The results of the survey showed an increase in the interest of interns in the use of information technology in the teaching of professional disciplines. At the Department of Neurology of the Odesa National Medical University, at all stages of the interns' training, the means of programmed control are actively used. The expediency of regular review of educational programs for the training of interns in the specialty of Neurology is shown considering the possibilities of modern information technologies.

Conclusion. Taking into account the priorities of interns training in the field of Neurology with the wide introduction of modern information technologies, it allows to improve theoretical knowledge and practical skills, to optimize the interaction in the format of multidisciplinary team with specialists of other specialties.

Key words: postgraduate education; information technologies; neurology.

Вступ. На сьогодні спеціальність “Неврологія” $\epsilon$ однією з найбільш затребуваних в Україні, щоро-

(ㄱ Т. М. Муратова, О. М. Лебідь, Д. М. Храмцов та ін. ку в інтернатурі за цим фахом навчається близько 300 осіб, і ще 300-500 проходять перепідготовку після одержання сертифікатів за іншими спеці- 
альностями [15]. Як правило, мотивація інтернів $є$ достатньо високою - адже ж більше 70 \% 3 них навчаються за контрактні кошти. Втім, традиційні засоби навчання, відсутність доступу до сучасних освітніх технологій та недостатня увага вітчизняних вишів до інтеграції в систему ліцензування майбутніх спеціалістів принципів continuous medical education (CME) й розширення ролі фахових асоціацій певною мірою обмежують ефективність навчального процесу. Наразі основна увага приділяється поновленню та вдосконаленню методичних розробок лекцій, практичних та семінарських занять, залученню принципів проблемного навчання. Значний обсяг роботи пов'язаний із регулярним поповненням банку тестів ректорського контролю та фахових іспитів [1, 15].

Наразі застосування інформаційних технологій у викладанні фахових дисциплін майбутнім неврологам обмежується використанням мультимедійних презентацій, фільмів, електронних підручників та атласів, навчальних дисків [3-9]. Частина цих освітніх ресурсів розміщена на сайті кафедри. Певне значення мають можливості соціальних мереж, у тому числі Facebook, Linkedin, Researchgate [6]. Значно рідше використовується дистанційне навчання (quiz-портали, вебінари, онлайн-курси, проекти “віртуальний неврологічний пацієнт”) [2, 9-15]. Розвиток цього напрямку стримується відсутністю вітчизняних спеціалізованих освітніх платформ, значною вартістю онлайнкурсів, які проводять фахівці Західної Європи, Канади та США.

3 метою формування практичних навичок можуть використовуватися ділові ігри, клінічні розбори хворих, семінари, дискусійні клуби, науково-практичні, клінічні та патологоанатомічні конференції. В останні роки доступними для вітчизняних медичних вишів стали технології симуляційної медицини. Наприклад, опанування техніки виконання люмбальної пункції за допомогою манекенів, застосування програмного забезпечення Body Interact $^{\mathrm{TM}}$ тощо [2, 3, 9-12].

Мета роботи - оцінка перспектив застосування сучасних інформаційних технологій при навчанні в інтернатурі за фахом “Неврологія”.

Основна частина. Проведений аналіз досвіду застосування різних інформаційних технологій при викладанні фахових дисциплін інтернам, що навчаються за фахом “Неврологія”. Проаналізовані результати проміжних та кінцевих контролів за 2015-2018 рр., визначений вплив від впровадження елементів інформаційних технологій у систему підготовки фахівців на етапі післядипломної освіти. Додатково проведено анкетування викладачів (12 осіб) та інтернів (35 осіб) щодо доцільності та ефективності застосування різних інформаційних технологій. Статистична обробка проводилася методами дисперсійного аналізу за допомогою пакета Statistica 13.0.

Як показав аналіз матеріалів дослідження, за останні три роки значно покращилася поінформованість викладачів з питань можливості застосування різних інформаційних технологій у викладанні фахових дисциплін (табл. 1). Якщо у 2015 р. основними формами, які активно застосовувалися, були засоби програмованого контролю та електронні підручники, то у 2018 р. до них приєдналися телеконференції, застосування мультимедійних симуляційних технологій, розсилки навчальних матеріалів в електронному вигляді, використання електронних репозиторіїв тощо.

Абсолютно інноваційною є технологія BODY INTERACT тм, яка надає можливість інтеграції у процес вивчення новітніх досягнень медицини та інформаційних технологій, розробки навчальних концепцій та обміну досвідом через реальні

Таблиця 1. Обізнаність респондентів-викладачів щодо застосування інформаційних технологій у лікуванні

\begin{tabular}{|l|c|c|c|c|c|c|c|c|}
\hline \multirow{2}{*}{ Форми навчальних технологій } & \multicolumn{2}{|c|}{$\begin{array}{c}2015 \\
(\mathrm{n}=9)\end{array}$} & \multicolumn{2}{c|}{$\begin{array}{c}2016 \\
(\mathrm{n}=10)\end{array}$} & \multicolumn{2}{c|}{$\begin{array}{c}2017 \\
(\mathrm{n}=12)\end{array}$} & \multicolumn{2}{c|}{$\begin{array}{c}2018 \\
(\mathrm{n}=12)\end{array}$} \\
\cline { 2 - 10 } & абс. & $\%$ & абс. & $\%$ & абс. & $\%$ & абс. & $\%$ \\
\hline Програмовані засоби контролю & 9 & 100 & 10 & 100 & 12 & 100 & 12 & 100 \\
\hline Електронні розсилки & 2 & 22,2 & 3 & 30,0 & 7 & 58,3 & 9 & 75,0 \\
\hline Групи в соціальних мережах & 1 & 11,1 & 3 & 30,0 & 5 & 41,7 & 6 & 50,0 \\
\hline Телеконференції & - & - & 1 & 10,0 & 3 & 25,0 & 4 & 33,3 \\
\hline Онлайн-відеолекції/презентації & 1 & 11,1 & 5 & 50,0 & 6 & 50,0 & 8 & 66,7 \\
\hline Е-репозиторії & 1 & 11,1 & 5 & 50,0 & 7 & 58,3 & 9 & 75,0 \\
\hline Воду Intеract & - & - & - & - & 1 & 8,3 & 7 & 58,3 \\
\hline Електронні підручники & 9 & 100 & 10 & 100 & 12 & 100 & 12 & 100 \\
\hline
\end{tabular}


клінічні ситуації, створюючу основу для культури відкритих комунікацій і співробітництва.

За період аналізу академічна успішність інтернів практично не змінилася, медіана оцінки на проміжних контролях складала 4 (3;4), на кінцевих 4 (3;5). Водночас результати опитування показали зростання зацікавленості як інтернів, так і викладачів у застосуванні інформаційних технологій при викладанні фахових дисциплін (рис. 1).

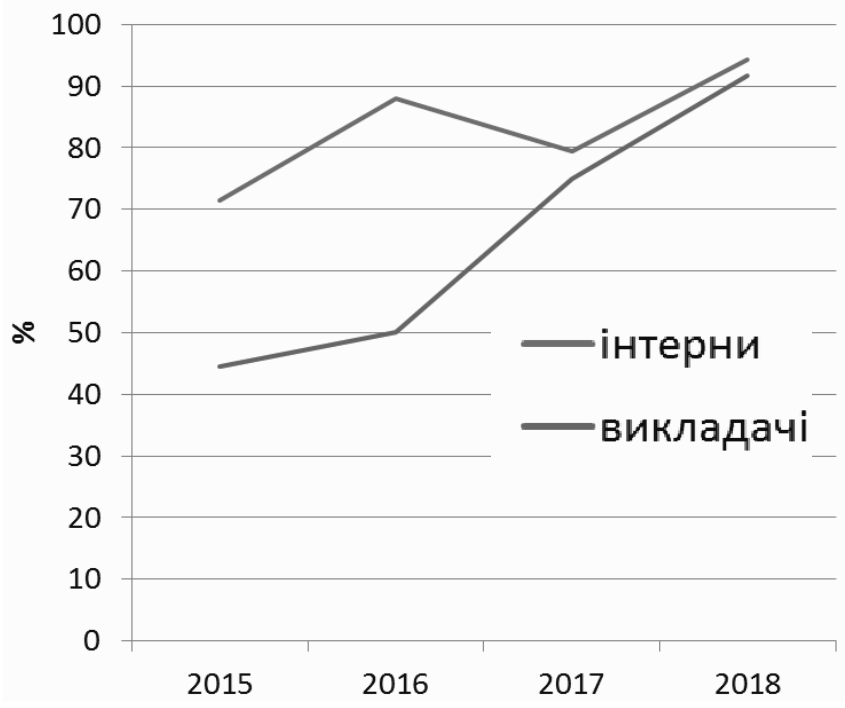

Рис. 1. Зацікавленість респондентів у застосуванні інформаційних технологій при викладанні фахових дисциплін.

Одним із найбільш ефективних засобів навчання $€$ побудований на основі 3D віртуальних інтерактивних технологій комплекс Body Interact ${ }^{\mathrm{TM}}$, який імітує візуально-просторові та інші характеристики стану здоров’я пацієнта в реальному часі, забезпечує реалістичний зворотний зв’язок, містить інструменти контролю якості засвоєння навичок, дозволяє проводити моніторинг і обстеження в режимі реального часу [2]. Найбільш ефективним комплекс виявився при викладанні невідкладної неврології та інсультології.

Для роботи з Body Interact тм викладач отримує спеціальну ліцензію, до якої входять доступ відстеження та інструменти управління продуктивністю 3 можливістю вирішувати, які сценарії доступні для студентів у будь-який час.

Інтуїтивно зрозумілий інтерфейс дозволяє налаштувати і запустити модуль “Об’ єктних структурованих клінічних досліджень”. Це дозволяє забезпечити повне обговорення результатів роботи за окремим клінічним випадком та вивести результати на візуальну панель, що відображає показни- ки ефективності кожного інтерна або всієї групи. Як варіант, кожному студенту може бути наданий індивідуальний доступ до платформи та випадків, вибраних викладачем.

Невід'ємною складовою опрацювання практичних навичок лікарями-інтернами залишається курація хворих. Для полегшення роботи інтерна використовуються електронні шаблони медичної документації, в тому числі макроси, що містять альтернативні ознаки, якісні та напівкількісні характеристики, необхідні при заповненні історії хвороби.

На кафедрі неврології Одеського національного медичного університету створені набори тестових завдань для визначення вихідного рівня знань, умінь лікарів-інтернів, поточного та підсумкового контролю. Наприкінці очного циклу проводиться етапний контроль навчання у вигляді диференційованого заліку. На всіх етапах підготовки інтернів широко застосовуються засоби програмованого контролю. Як свідчить досвід інших вищих навчальних закладів і власний, підготовка фахівців на сучасному рівні без інформаційних і телекомунікаційних технологій неможлива $[1,5,8,11]$.

Ефективність підготовки на заочних базах значною мірою залежить від особистості безпосереднього керівника лікаря-інтерна, його кваліфікації та педагогічної майстерності. На кафедрі неврології за базами закріплені викладачі, які мають достатній досвід роботи в системі післядипломної освіти. Додатково на регулярній основі здійснюється виїзд викладачів з числа професорів та доцентів кафедри на бази інтернатури з метою надання методичної допомоги, читання лекцій з актуальних питань неврології, проведення показових клінічних розборів тощо.

На завершальному етапі навчання в інтернатурі кожен інтерн під керівництвом персонально закріпленого асистента готується до контрольного тестування, спеціально і поглиблено вивчає питання діагностики та допомоги при невідкладних станах, у тому числі із використанням сучасних інформаційних технологій. Засобом контролю якості освіти в інтернатурі на державному рівні $є$ ліцензійний іспит “Крок-3”, основним елементом якого є складання тестового контролю знань. Підсумковий контроль знань і умінь здійснюється шляхом атестації лікарів-інтернів, який передбачає проходження тестування із використанням програмованих засобів навчання.

Слід зазначити, що навчальні програми для навчання лікарів-інтернів неврологів постійно пере- 
глядаються, що дозволяє більш широко застосовувати сучасні інформаційні технології. Натомість типова програма не переглядалася вже з десяток років.

Висновок. Врахування пріоритетів підготовки лікарів-інтернів за фахом “Неврологія” із широким

\section{Список літератури}

1. Новикова Л. Б. 10-летний опыт последипломного обучения врача-невролога на кафедре неврологии и нейрохирургии ИПО БГМУ / Л. Б. Новикова, А. П. Акопян, Л. Р. Шарафутдинова // Вестник Башкирского государственного медицинского университета. - 2012. - № 2. С. 112-119.

2. Body Interact [Electronic resource]. - Mode access : https://bodyinteract.com/.

3. Dhand A. Leadership in neurology: a social network analysis / A. Dhand, J. Harp, S. P. Borgatti // Ann. Neurol. 2014. - Vol. 75 (3). - P. 342-350.

4. Hei Cu Med. Heidelberg Curriculum Medicinale / Virtual Patients in Neurology [Electronic resource]. - Mode access : http://www.medizinische-fakultaet-hd.uni-heidelberg. de/fileadmin/kompzent/Juenger_Heicumed_Med_Aus.pdf.

5. Ананьева Е. С. Использование методов проблемного обучения в ходе изучения дисциплины "Неврология” / Е. С. Ананьева, В. А. Быкова // Личность, семья и общество: вопросы педагогики и психологии. - 2014. № 42. - С. 29-34.

6. Бабієнко В. В. Використання соціальних мереж при викладанні освітніх дисциплін / В. В. Бабієнко, Ю. Г. Романова // Медична освіта. - 2014. - № 3 (дод.). С. 208-210.

7. Васильев Ю. Н. Организация обучения в интернатуре по специальности “Неврология” на кафедре нервных болезней: проблемы и перспективы / Ю. Н. Васильев, Ю. Н. Быков // Система менеджмента качества: опыт и перспективы. - 2015. - № 4. - С. 201-203.

8. Головченко Ю. П. Особенности обучения семейных врачей на кафедре неврологии / Ю. П. Головченко, Е. И. Асауленко // Семейная медицина. - 2012. - № 4. C. 102.

9. Исаева Н. В. Способы привлечения и поддержания внимания обучающихся в течение лекции на курсе "Неврология” в системе последипломного образования / Н. В. Исаева, И. В. Евсеева // Современные тенденции развития педагогических технологий в медицинском образовании. Вузовская педагогика : материалы конфе-

\section{References}

1. Novikova, L.B., Akopyan, A.P., \& Sharafutdinova, L.R. (2012). 10-letniy opyt poslediplomnogo obucheniya vrachanevrologa na kafedre nevrologii i neyrokhirurgii ipo BGMU [10-year experience of postgraduate training of a neurologist at the Department of Neurology and Neurosurgery of the впровадженням сучасних інформаційних технологій дозволяє вдосконалити теоретичні знання та практичні навички, оптимізувати взаємодію у форматі мультидисциплінарної команди з фахівцями інших спеціальностей.

ренции / главный редактор С. Ю. Никулина. - 2016. С. $178-180$.

10. Лалов Ю. В. Методы эвристического обучения как средство формирования ценностных ориентаций у студентов медицинского вуза на практических занятиях по неврологии / Ю. В. Лалов, О. Л. Осадчук // Международный журнал прикладных и фундаментальных исследований. - 2015. - № 4-1. - С. 133-136.

11. Ласков В. Б. Учебно-воспитательный процесс на кафедре неврологии и нейрохирургии: объективные и субъективные аспекты оценочных суждений студентов / В. Б. Ласков // Коллекция гуманитарных исследований. - 2016. - № 1 (1). - С. 39-45.

12. Лопанова Е. В. Электронные учебные пособия как элемент информационно-образовательной среды кафедры медицинского вуза / Е. В. Лопанова, Ю. В. Лалов // Ученые записки ИУО РАО. - 2017. - № 1-2 (61). С. 69-72.

13. Николаева Т. Я. Интерактивные методы обучения в неврологии / Т. Я. Николаева, С. А. Чугунова, Э. Э. Конникова // Вестник Северо-Восточного федерального университета им. М. К. Аммосова. Серия “Медицинские науки”. - 2017. - № 1 (06). - С. 55-58.

14. О преподавании теоретических вопросов на послевузовском этапе профессионального образования по специальности “Неврология” / О. П. Ковтун, О. А. Львова, К. С. Невмержицкая [и др.] // Системная интеграция в здравоохранении. - 2009. - № 3. - С. 46-51.

15. Свиридова Н. К. Особливості навчання в інтернатурі з неврології в сучасних умовах / Н. К. Свиридова, Р. В. Сулік, Г. С. Кусткова // Восточно-европейский неврологический журнал [Электронный ресурс]. - Режим доступа : http://journal.nevrology.info/index.php/stati/ item/10-osoblivosti-navchannya-v-internaturi-z-nevrologijiv-suchasnikh-umovakh.

16. Дамулин И. В. Проблемы и перспективы обучения неврологии в современных условиях / И. В. Дамулин, Р. В. Шурупова // Журнал неврологии и психиатрии им. С. С. Корсакова. - 2014. - Т. 114, № 11-1. - С. 84-87.

Belarusian State Medical University]. Vestnik Bashkirskogo gos. med. un-ta - Bulletin of the Bashkir State Medical University, 2, 112-119 [in Russsian].

2. Body Interact. Electronic resource. Retrieved from: https://bodyinteract.com/. 
3. Dhand, A., Harp, J., \& Borgatti, S.P. (2014). Leadership in neurology: a social network analysis. Ann. Neurol., 75 (3), 342-350.

4. HeiCuMed. Heidelberg Curriculum Medicinale / Virtual Patients in Neurology. Electronic resource. Retrieved from: http://www.medizinische-fakultaet-hd.uni-heidelberg. de/fileadmin/kompzent/Juenger_Heicumed_Med_Aus.pdf.

5. Ananyeva, E.S., \& Bykova, V.A. (2014). Ispolzovanie metodov problemnogo obucheniya $\mathrm{v}$ khode izucheniya distsipliny "Nevrologiya" [The use of methods of problembased training in the study of the discipline "Neurology"]. Lichnost, semya i obshchestvo: voprosy pedagogiky $i$ psikhologii - Personality, Family and Society: Questions of Pedagogy and Psychology, 42, 29-34 [in Russian].

6. Babiienko, V.V., \& Romanova, Yu. H. (2014). Vykorystannia sotsialnykh merezh pry vykladanni osvitnikh dystsyplin [The use of social media in teaching educational disciplines]. Medychna osvita - Medical Education, 3, 208210 [in Ukrainian].

7. Vasilyev, Yu.N., \& Bykov, Yu.N. (2015). Organizatsiya obucheniya v internature po spetsialnosti "Nevrologiya" na kafedre nervnykh bolezney: problem i perspektivy [Organization of training in internship in the specialty "Neurology" at the Department of Nervous Diseases: problems and prospects]. Sistema menedzhmenta kachestva: opyt i perspektivy - Quality Management System: Experience and Prospects, 4, 201-203 [in Russian].

8. Golovchenko, Yu.P., \& Asaulenko, E.I. (2012). Osobennosti obucheniya semeynykh vrachey na kafedre nevrologii [Features of teaching family doctors at the Department of Neurology]. Semeynaya meditsina - Family Medicine, 4, 102 [in Russian].

9. Isayeva, N.V., \& Evseeva, I.V. (2016). Sposoby privlecheniya i podderzhaniya vnimaniya obuchayushchikhsya v techeniye lektsii na kurse "Nevrologiya" v sisteme poslediplomnogo obrazovaniya [Ways to attract and maintain the attention of students during the lecture on the course of Neurology in the system of postgraduate education]. Materialy konferentsii Sovremennye tendetntsii razvitiya pedagogicheskikh tekhnologiy $v$ meditsinskom obrazovanii. Vuzovskaya pedagogika - Materials of Conference: Modern trends in the development of pedagogical technologies in medical education. University pedagogy Conference materials. (pp. 178-180) [in Russian]

10. Lalov, Yu.V., \& Osadchuk, O.L. (2015). Metody evrisicheskogo obucheniya kak sredstvo formirovaniya tsennostnykh oriyentatsiy u studentov meditsinskogo vuza na prakticheskikh zanyatiyakh po nevrologii [Methods of heuristic learning as a means of forming value orientations of medical students at practical classes in neurology]. Mezhdunarodnyy zhurnal prikladnykh i fundamentalnykh issledovaniy - International Journal of Applied and Fundamental Research, 4-1, 133-136 [in Russian].

11. Laskov, V.B. (2016). Uchebno-vospitatelnyy protsess na kafedre nevrologii i neyrokhirurgii: Obyektivnyye i subyektivnye aspekty otsenochnykh suzhdeniy studentov [The educational process at the department of neurology and neurosurgery: the objective and subjective aspects of the evaluative judgments of students]. Kollektsiya gumanitarnykh issledovaniy - Collection of Humanitarian Studies, 1 (1), 39-45 [in Russian].

12. Lopanova, E.V., \& Lalov, Yu.V. (2017). Elektronnye uchebnye posobiya kak element informatsionnoobrazovatelnoy sredy kafedry meditsinskogo vuza [Electronic textbooks as an element of the informationeducational environment of the department of medical high school]. Uchenye zapiski IUO RAO - Scientific Notes of IUO RAO, 1-2 (61), 69-72 [in Russian].

13. Nikolaeva, T.Ya., Chugunova, S.A., \& Konnikova, E.E. (2017). Interaktivnye metody obucheniya v nevrologii [Interactive teaching methods in neurology]. Vestnik SeveroVostochnogo federalnogo universiteta im. M. K. Ammosova. Seriya "Meditsinskiye nauki" - Bulletin of the NorthEastern Federal University. M.K. Ammosov. Series: Medical Sciences, 1 (06), 55-58 [in Russian].

14. Kovtun, O.P., Lvova, O.A., Nevmerzhitskaya, K.S., Koryakina, O.V., \& Ovsova, O.V. (2009). O prepodavanii teoreticheskikh voprosov na poslevuzovskom etape professionalnogo obrazovaniya po spetsialnosti "Nevrologiya" [On the teaching of theoretical issues at the postgraduate stage of vocational education in the specialty of Neurology]. Sistemnaya integratsiya $v$ zdravookhranenii - System Integration in Healthcare, 3, 46-51 [in Russian].

15. Sviridova, N.K., Sulyk, R.V., \& Kustkova, H.S. Osoblyvosti navchannia $\mathrm{v}$ internaturi z nevrolohii v suchasnykh umovakh [Special features in the internship of neurology in the minds of the day]. Vostochno-yevropeyskiy nevrologicheskiy zhurnal - East European Neurological Journal. Electronic resource. Retrieved from: http://journal.nevrology.info/index.php/stati/item/10-osoblivosti-navchannyav-internaturi-z-nevrologiji-v-suchasnikh-umovakh [in Russian].

16. Damulin, I.V., \& Shurupova, R.V. (2014). Problemy i perspektivy obucheniya nevrologii v sovremennom usloviyakh [Problems and prospects of teaching neurology in modern conditions]. Zhurnal nevrologii i psikhiatrii im. S.S. Korsakova - S.S. Korsakov Journal of Neurology and Psychiatry, 114 (11-1), 84-87 [in Russian]. 